\title{
Zoledronic acid inhibits proliferation of human fibrosarcoma cells with induction of apoptosis, and shows combined effects with other anticancer agents
}

\author{
KAZUTAKA KOTO ${ }^{1,2}$, HIROAKI MURATA ${ }^{1}$, SHINYA KIMURA ${ }^{3}$, NAOYUKI HORIE ${ }^{1}$, TAKAAKI MATSUI ${ }^{1}$, \\ YASUNORI NISHIGAKI ${ }^{1}$, KAZUTERU RYU ${ }^{1}$, TOMOYA SAKABE ${ }^{1}$, MEGUMI ITOI $^{1}$, EISHI ASHIHARA ${ }^{4}$, \\ TAIRA MAEKAWA ${ }^{4}$, SHINJI FUSHIKI ${ }^{2}$ and TOSHIKAZU KUBO ${ }^{1}$ \\ Departments of ${ }^{1}$ Orthopaedics, and ${ }^{2}$ Pathology and Applied Neurobiology, Graduate School of Medical Science, \\ Kyoto Prefectural University of Medicine, 465 Kawaramachi-Hirokoji, Kamigyo-ku, Kyoto 602-8566; \\ ${ }^{3}$ Division of Hematology, Respiratory Medicine, and Oncology, Department of Internal Medicine, Faculty of Medicine, \\ Saga University, 5-1-1 Nabeshima, Saga 849-8501; ${ }^{4}$ Department of Transfusion Medicine and Cell Therapy, \\ Kyoto University Hospital, 54 Kawahara-cho Shogoin, Sakyo-ku, Kyoto 606-8507, Japan
}

Received February 25, 2010; Accepted March 31, 2010

DOI: $10.3892 /$ or_00000851

\begin{abstract}
Third-generation bisphosphonates are known to inhibit bone resorption and also appear to exhibit direct antitumour activity. We previously reported that third-generation bisphosphonates such as zoledronic acid (ZOL) have a direct antitumour effect, and synergistically augment the effects of antitumor agents in osteosarcoma cells. There has been no report on the antitumor effect of ZOL against soft tissue sarcoma. The aim of this study was to evaluate the antitumor effect of this drug on a human fibrosarcoma cell line, in terms of proliferation and apoptosis, and, moreover, to evaluate the combined effects of ZOL with other antitumor drugs against the human fibrosarcoma cell line. HT1080 cells were treated with ZOL at various concentrations up to $10 \mu \mathrm{M}$, and then cell proliferation, cell cycle, nuclear morphology, and Western blot analyses were performed to study the antitumor effects of ZOL alone, and, moreover, HT1080 cells were treated with ZOL and other anticancer drugs such as paclitaxel, docetaxel, doxorubicin, etoposide, 5-fluorouracil, gemcitabine, cisplatin, or methotrexate to investigate the combined effects using proliferation and cell cycle analyses. We found that ZOL strongly inhibited in vitro proliferation, arrested the cell cycle
\end{abstract}

Correspondence to: Dr Hiroaki Murata, Department of Orthopaedics, Graduate School of Medical Science, Kyoto Prefectural University of Medicine, 465 Kawaramachi-Hirokoji, Kamigyo-ku, Kyoto 602-8566, Japan

E-mail:murah@koto.kpu-m.ac.jp

Abbreviations: ZOL, zoledronic acid; FPP, farnesyl diphosphate; DAPI, 4',6-diamidino-2-phenylindole dihydrochloride

Key words: fibrosarcoma, bisphosphonates, zoledronic acid, apoptosis, cell cycle arrest, combined effects between $\mathrm{S}$ and $\mathrm{G} 2 / \mathrm{M}$ phases, and induced the apoptosis of human fibrosarcoma cells. Moreover, ZOL augmented the effect of antitumor agents when administered concurrently with paclitaxel, docetaxel, doxorubicin, etoposide, 5-fluorouracil, gemcitabine, and cisplatin in human fibrosarcoma cells. The treatment of fibrosarcoma with ordinary antitumor drugs is not fully effective. These findings suggest that $\mathrm{ZOL}$ directly affects the proliferation and survival of fibrosarcoma cells, and that the combined administration of ZOL with other antitumor agents may improve the efficacy of fibrosarcoma treatment. These results support the possibility that their combined use could be beneficial in the treatment of patients not only with various types of cancer or osteosarcoma, but also with soft tissue sarcoma.

\section{Introduction}

Fibrosarcoma is one of the high-grade malignant soft tissue sarcomas that commonly occurs in middle-aged and older adults. Fibrosarcoma involves deep soft tissues of the extremities, trunk, head, and neck. Although the prognosis of these patients has improved due to the development of surgical treatment and various adjuvant chemotherapies, these therapies are not fully effective. The probability of local recurrence is related to the completeness of excision, with recurrence rates of $12-79 \%$ (1-3). Fibrosarcoma metastasizes to the lungs and bone, especially the axial skeleton. Metastasis occurs in 9-63\% of patients, and is time- and grade-dependent. The 5-year survival rate of these patients is still $39-54 \%(2,3)$. For the improvement of treatment, novel antitumor drugs are urgently required.

Recently, many investigators have reported that bisphosphonates can directly inhibit the growth of various malignant cells, including multiple myeloma $(4,5)$, leukemia (6), prostate cancer $(7)$, and chondrosarcoma $(8,9)$. Bisphosphonates are effective inhibitors of bone resorption and have been used for the last three decades in the treatment of 
metabolic bone diseases (10). Nitrogen-containing bisphosphonates, or so-called second- and third-generation bisphosphonates, inhibit the activity of farnesyl diphosphate synthase (FPP synthase). This enzyme is required for the production of isoprenoid lipids necessary for the prenylation of small GTPases (11-13).

The inhibition of FPP synthase by nitrogen-containing bisphosphonates indirectly prevents protein prenylation, causing a loss of osteoclast function and apoptosis $(14,15)$.

Third-generation bisphosphonates, such as zoledronic acid (ZOL), are 10,000- to 100,000-fold more potent than the older-generation bisphosphonates (16). ZOL, the most potent nitrogen-containing bisphosphonate clinically available, has shown efficacy against bone cancer metastasis due to prostate cancer and other solid tumors, demonstrating that nitrogen-containing bisphosphonates can reduce skeletal morbidity in both osteolytic and osteoblastic diseases $(35,36)$.

Recent pre-clinical in vitro and in vivo models have provided evidence that high doses of bisphosphonates may not only reduce bone loss through the inhibition of osteoclast activity, but may also exert direct antitumor and antiangiogenic effects. Moreover, preclinical data have revealed that nitrogen-containing bisphosphonates can act on tumor cells by inhibiting tumor cell adhesion to mineralized bone as well as tumor cell invasion and proliferation (19-21).

We have also reported that bisphosphonates exhibit antitumor effects against osteosarcoma cells in in vitro and in vivo models $(22,23)$, and that ZOL synergistically augments the effect of antitumor agents in osteosarcoma cell lines (23). Likewise, there are some reports concerning the combined effect of third-generation bisphosphonates with antitumor agents in various cancer cell lines (25-30).

For these reasons, bisphosphonates are assumed to be effective in inhibiting the growth of soft tissue sarcoma cells, by inhibiting the activity of FPP synthase. However, there has been no report on the antitumor effect of bisphosphonates against soft tissue sarcoma cells.

In this study, our purpose was to investigate the direct antitumor effect of ZOL against fibrosarcoma cells, which comprise one of the soft tissue sarcoma cell lines. To our knowledge, there has been no report on this tumor. Furthermore, we investigated the concurrent, combined effect of ZOL with other antitumor agents such as doxorubicin, etoposide, and paclitaxel.

\section{Materials and methods}

Reagents. ZOL (1-hydroxy-2-(1H-imidazole-1-yl) ethylidene-bisphosphonic acid) was obtained from Novartis Pharma AG (Basel, Switzerland). Doxorubicin (from Toronto Research Chemicals, Inc., Toronto, Canada), 5-fluorouracil (from Nacalai Tesque, Inc., Kyoto, Japan), cisplatin, paclitaxel, docetaxel, gemcitabine (from LKT laboratories, Inc., St. Paul, MN, USA), etoposide (from CalbiochemNovabiochem, Cor(Merck KGaA), Darmstadt, Germany), and methotrexate (from Sigma Aldrich, Tokyo, Japan) were purchased from commercial sources. Appropriate drug concentrations were made by dilution with fresh medium immediately before each experiment.

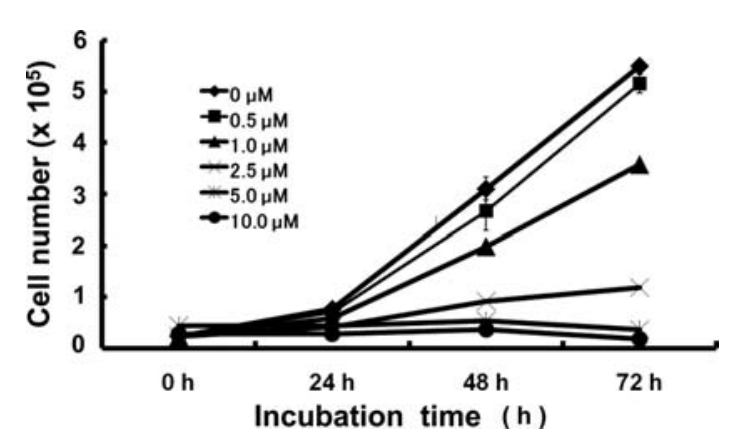

Figure 1. Effects of ZOL on HT1080 cell growth. HT1080 cells were exposed to $0(\bullet), 0.5(\bullet), 1.0(\bullet), 2.5(\times), 5.0(*)$, or $10.0(\bullet) \mu \mathrm{M}$ ZOL. Viable cells were counted by employing the trypan blue dye exclusion method. The data are presented as the means \pm SD of at least three independent experiments.

Cell line. The characteristics of the human fibrosarcoma cell line HT1080 (parental) were described previously by M.L. Slovak (Department of Cytogenetics, City of Hope National Medical Center, Duarte, CA, USA) $(31,32)$. These cells were cultured in RPMI-1640 medium (Nacalai Tesque, Inc.) supplemented with $10 \%$ fetal calf serum (FCS) and an antibiotic solution of penicillin (100 units/ml) and streptomycin $(100 \mu \mathrm{g} / \mathrm{ml})$. All cells were cultured at $37^{\circ} \mathrm{C}$ in a fully humidified incubator with $5 \% \mathrm{CO}_{2}$. All experiments described were performed at least three times using cells in the exponential growth phase.

Effects of ZOL on cell proliferation. Cell growth and viability were evaluated employing the trypan blue dye exclusion method. HT1080 cells were incubated in 6-well plates at a density of $2 \times 10^{4}$ in $2 \mathrm{ml}$ of medium per well for $24 \mathrm{~h}$, followed by the addition of $0,0.5,1.0,2.5,5.0$, and $10.0 \mu \mathrm{M}$ of ZOL. The viable cells in each well were counted at 0 , 24,48 , and $72 \mathrm{~h}$ in vitro with a hemocytometer using the trypan blue dye exclusion method. The results are shown as means $\pm \mathrm{SD}$. The $50 \%$ growth inhibitory concentrations $\left(\mathrm{IC}_{50}\right)$ of $\mathrm{ZOL}$ were determined using the non-linear regression program CalcuSyn (Biosoft, Cambridge, UK).

Cell cycle analysis by flow cytometry. Untreated HT1080 cells or HT1080 cells treated with ZOL for 24, 48, and $72 \mathrm{~h}$ were analyzed for cell cycle alterations by staining with propidium iodide (Sigma Aldrich). The stained nuclei were analyzed using a FACSCalibur flow cytometer (BectonDickinson, Tokyo, Japan). DNA histograms were created using Cell Quest software for Apple Macintosh (BectonDickinson).

Analysis of nuclear morphology. Untreated HT1080 cells and HT1080 cells treated with $2.5 \mu \mathrm{M}$ ZOL were cultured for $48 \mathrm{~h}$, fixed with $2 \%$ paraformaldehyde in PBS for $10 \mathrm{sec}$, and then stained with DAPI (4',6-diamidino-2-phenylindole dihydrochloride) (Nacalai Tesque) at $4^{\circ} \mathrm{C}$ in the dark. For fluorescence microscopy, cells were cytospun onto slides and examined using a universal microscope (Nikon, Tokyo, Japan) with UV illumination. Apoptotic cells were defined on the basis of characteristic changes including nuclear condensation, fragmentation, and apoptotic bodies. 
A

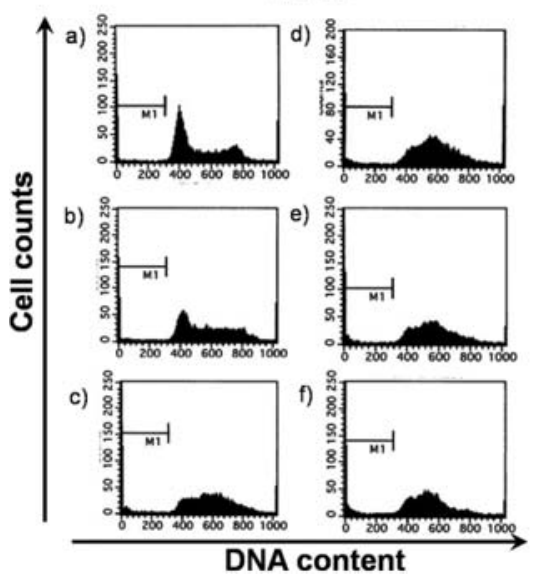

B

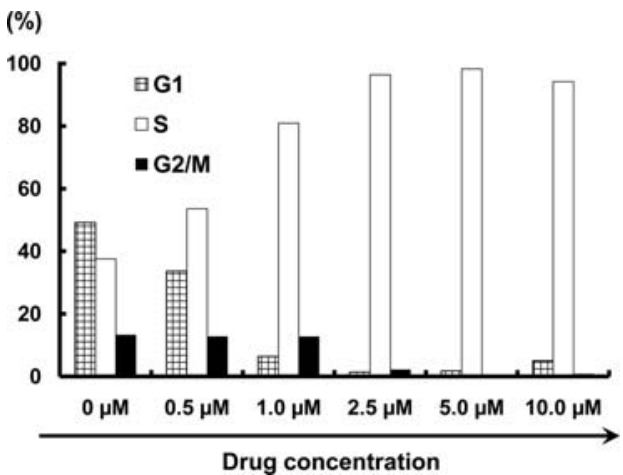

$48 \mathrm{~h}$

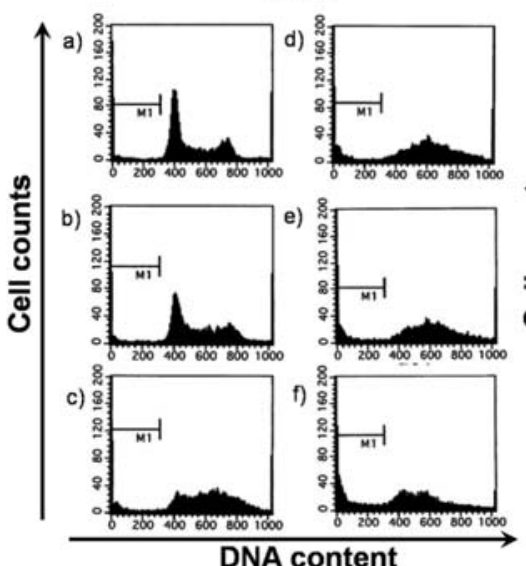

C
$72 \mathrm{~h}$

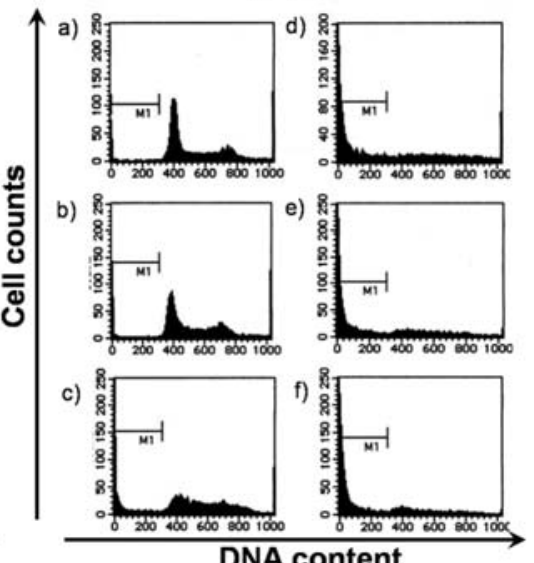

Sub-G1 (\%)

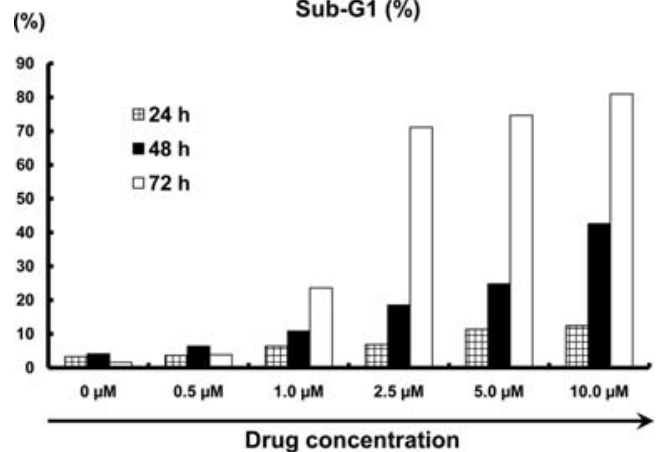

Figure 2. (A and B) ZOL altered the cell cycle in HT1080 cells. The effect of ZOL on the cell cycle was evaluated employing flow cytometry in HT1080 cells exposed to different concentrations: a) 0, b) 0.5 , c) 1.0 , d) 2.5 , e) 5.0 , and f) $10.0 \mu \mathrm{M} \mathrm{ZOL} \mathrm{for} \mathrm{24,} \mathrm{48,} \mathrm{or} \mathrm{72} \mathrm{h} \mathrm{(A).} \mathrm{The} \mathrm{proportion} \mathrm{of} \mathrm{HT1080} \mathrm{cells}$ between the G1- and G2-phases increased to $>80 \%$ when they were treated with over $1.0 \mu \mathrm{M}$ of ZOL for $48 \mathrm{~h}$ (B). The data shown are representative of three independent experiments. (C). HT1080 cells in the sub-G1 increased in a time- and dose-dependent manner. Low concentrations of ZOL did not increase the proportion of sub-G1, but high concentrations caused HT1080 cells in sub-G1 to increase.

Western blot analysis. To extract HT1080 proteins, the cells were seeded in culture dishes with various concentrations of ZOL for 24-72 h. Protein samples were extracted from $3 \times 10^{6}$ cells, separated by sodium dodecyl sulfate-polyacrylamide gel electrophoresis, and blotted onto a nitrocellulose membrane (Amersham Biosciences, Tokyo, Japan). The membranes were saturated with $5 \%$ (wt/vol) non-fat dry milk in TBST [25 mM Tris $\mathrm{HCl}$ (pH 7.8), $140 \mathrm{mM} \mathrm{NaCl}, 0.1 \%$ (vol/vol) Tween-20], and then incubated overnight with goat polyclonal anti-Rap1A antibody (diluted 1:1,000) (Santa Cruz Biotechnologies, CA, USA). Rap 1A is a substrate of geranylgeranyl transferase (GGTase I) (33). The membranes were washed thoroughly with TBST and incubated for $1 \mathrm{~h}$ with anti-goat $\mathrm{IgG}$ coupled with horseradish peroxidase (Santa Cruz Biotechnologies). Detection was performed with enhanced chemiluminescence kits (Amersham Biosciences).

Concurrent exposure to ZOL and other antitumor agents. To investigate the combined effect of ZOL with other antitumor agents, HT1080 cells were treated with $1.2 \mu \mathrm{M}$, which is about the $\mathrm{IC}_{50}$, of ZOL alone, antitumor drugs such as doxorubicin, cisplatin, etoposide, 5-fluorouracil, docetaxel, paclitaxel, gemcitabine, and methotrexate alone, and ZOL/ antitumor drug combinations in 6-well plates for $72 \mathrm{~h}$. The concentrations of these antitumor drug were $1.0 \mathrm{xIC}_{50}$ and $0.5 \times \mathrm{IC}_{50}$ of each. The $\mathrm{IC}_{50}$ after $72 \mathrm{~h}$ of each antitumor drug was decided employing the trypan blue dye exclusion method and calculated using the non-linear regression program CalcuSyn mentioned above. Proliferation of the cell lines was determined using the trypan blue dye exclusion method, as described above. HT1080 cells were incubated in 6-well plates at a density of $2 \times 10^{4}$ in $2 \mathrm{ml}$ of medium per well for $24 \mathrm{~h}$, followed by an additional $1.2 \mu \mathrm{M}$ of $\mathrm{ZOL}$ alone, other antitumor agents alone, and the ZOL/antitumor drug combination in 6-well plates for $72 \mathrm{~h}$. The viable cells in each well were counted at $72 \mathrm{~h}$ in vitro. The means of three data values for each treatment were calculated. The results are shown as means \pm SD. These cell cycles were also analyzed using the flow cytometry method described above. P-values $<0.05$ were considered significant, and were derived from two-sided statistical tests.

\section{Results}

Growth inhibition of fibrosarcoma cell lines by ZOL. ZOL inhibited the growth of HT1080 cells, as shown in Fig. 1. HT1080 cell growth was inhibited by ZOL in a time- and dose-dependent manner. The $\mathrm{IC}_{50}$ of ZOL after 48 and $72 \mathrm{~h}$ of exposure was 1.66 and $1.26 \mu \mathrm{M}$, respectively. Thus, ZOL effectively inhibited fibrosarcoma cell growth. Furthermore, a high concentration of ZOL over $2.5 \mu \mathrm{M}$ demonstrated a cytotoxic effect. 
Untreated

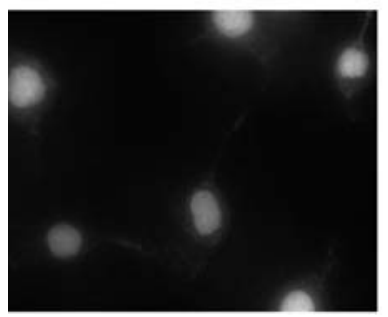

Figure 3. Untreated HT1080 cells or HT1080 cells treated with $2.5 \mu \mathrm{M}$ ZOL for $48 \mathrm{~h}$ were stained with DAPI. Pictures of the cells were taken in monochrome with fluorescence micrography (magnification, $\mathrm{x} 400$ ) and then dyed a pseudo color. The data shown are representative of three independent experiments.

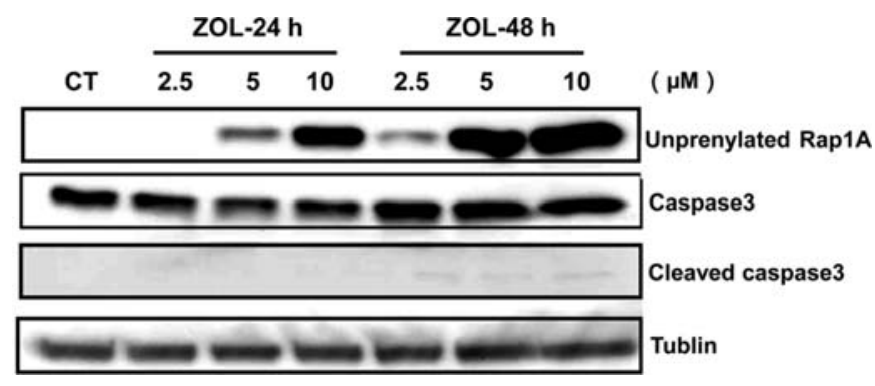

Figure 4. ZOL prevents the prenylation of Rap1A. Cell lysates from HT1080 cells treated with $2.5,5.0$, or $10.0 \mu \mathrm{M}$ ZOL for 24 or $48 \mathrm{~h}$ were subjected to Western blotting using an antibody specific for the unprenylated form of Rap1A, an antibody for cleaved caspase-3, and an antibody for tublin. The data shown are representative of three independent experiments.

Effect of ZOL on the cell cycle and induction of apoptosis in HT1080 cells. Cell cycle analysis were performed on HT1080 cells after 24,48 , or $72 \mathrm{~h}$ of concurrent exposure to ZOL to observe events on a DNA histogram. These results revealed an increase of cells in the $\mathrm{S}$ phase between the G0/G1 and $\mathrm{G} 2 / \mathrm{M}$ phases in a dose-dependent manner after 24 - or 48 -h concurrent exposure to ZOL (Fig. 2A and B). The proportion of cells in sub-G1 increased in a time- and dose-dependent manner, especially when they were exposed to a high concentration (over $2.5 \mu \mathrm{M}$ ) of ZOL (Fig. 2C). A low concentration of ZOL altered the cell cycle, and a high concentration induced an increase in Sub-G1 in human fibrosarcoma cells.

Effect of ZOL on nuclear morphology. HT1080 cells treated for $48 \mathrm{~h}$ with $2.5 \mu \mathrm{M}$ ZOL and stained with DAPI showed nuclear fragmentation and apoptotic bodies that are characteristic of apoptosis (Fig. 3).

Effect of ZOL on small GTP-binding protein prenylation and the induction of apoptosis in HT1080 cells. HT1080 cells treated for 24 and $48 \mathrm{~h}$ with 2.5, 5.0, and $10.0 \mu \mathrm{M}$ ZOL were lysed and analyzed by Western blotting using an antibody that specifically recognizes the unprenylated form of Rap1A and cleaved caspase-3. Unprenylated Rap1A was not detected in untreated HT1080 cells but accumulated markedly after treatment. Unprenylated Rap1A levels were increased further after $48 \mathrm{~h}$ of ZOL treatment, as well as after 5.0 and $10 \mu \mathrm{M}$
Table I. $\mathrm{IC}_{50}$ values of antitumor drugs for $72 \mathrm{~h}$.

\begin{tabular}{lr}
\hline Doxorubicin & $4.7 \mathrm{nM}$ \\
Cisplatin & $947.5 \mathrm{nM}$ \\
Etoposide & $135.0 \mathrm{nM}$ \\
5-fluorouracil & $178.2 \mathrm{nM}$ \\
Docetaxel & $6.9 \mathrm{nM}$ \\
Paclitaxel & $1.7 \mathrm{nM}$ \\
Gemcitabine & $87.7 \mathrm{nM}$ \\
Methotrexate & $8.7 \mathrm{nM}$ \\
\hline
\end{tabular}

treatment. Cleaved caspase- 3 was not detected in untreated HT1080 cells after $24 \mathrm{~h}$ of ZOL treatment, but was detected after 48-h treatment (Fig. 4).

Concurrent combined effects of ZOL with other antitumor agents. Cytotoxic interactions on the concurrent exposure of cells to $\mathrm{ZOL}$ and other antitumor drugs. The $\mathrm{IC}_{50}$ at $72 \mathrm{~h}$ of each antitumor drug is shown in Table I. When combined with a concentration of $0.5 \times \mathrm{IC}_{50}$ and $1.0 \times \mathrm{xC}_{50}$ values for doxorubicin, cisplatin, etoposide, 5-fluorouracil, docetaxel, paclitaxel, and gemcitabine, the growth inhibitory effects were much more markedly augmented compared to ZOL alone or antitumor drugs alone. When we used ZOL together with docetaxel or etoposide, the P-value was $<0.001$, and the combination effect was particularly marked. In contrast, when combined with methotrexate, The P-value exceeded 0.05 , indicating that combination with methotrexate has antagonistic rather than additive or synergistic effects. Only MTX did not show a combined effect (Fig. 5).

Effects of ZOL and other antitumor drugs on the cell cycle and induction of cell death. As described above, significant inhibitory effects of etoposide or docetaxel with ZOL were noted in HT1080 cells. To investigate the possible mechanisms, we analyzed the effects of these anticancer agents on the cell cycle. When HT1080 cells were treated with $1.2 \mu \mathrm{M}$ ZOL combined with $70 \mathrm{nM}$ (approximatelly equal to $0.5 \mathrm{xIC}_{50}$ ) or $140 \mathrm{nM}$ (approximatelly equal to $1.0 \mathrm{xIC}_{50}$ ) etoposide for $72 \mathrm{~h}$, there was an increase in the proportion of HT1080 cells only in sub-G1. In the histogram, the G1-, S-, and G2/M-phases were not so markedly changed by combined treatment compared to each drug alone. These results are similar to those for HT1080 cells treated with docetaxel, doxorubicin, cisplatin, 5-fluorouracil, paclitaxel, and gemcitabine for $72 \mathrm{~h}$. These suggest that when ZOL is combined with etoposide or other anticancer agents except for methotrexate, ZOL might augment the cytotoxic effect of anticancer agents (Fig. 6, Table II).

\section{Discussion}

We have demonstrated that the third-generation bisphosphonate, ZOL, inhibits the proliferation of fibrosarcoma cell lines. As far as we know, there have been no reports on the antitumor effect of bisphosphonates on soft tissue 

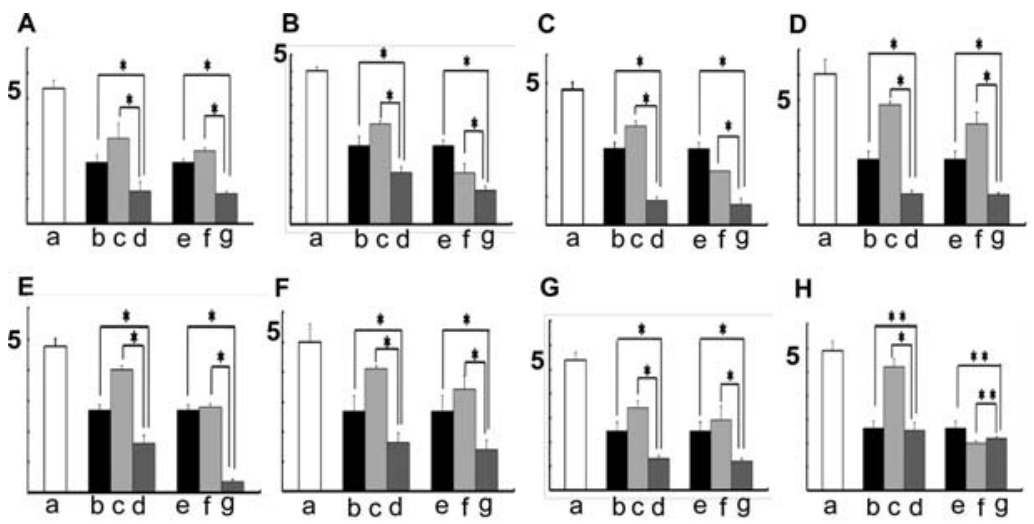

H

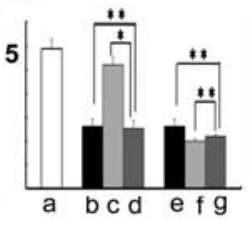

*:P $\mathrm{P} 0.05$

**: $\mathrm{P} \geqq 0.05$

Figure 5. Growth inhibitory effects of concurrent treatment with ZOL and anticancer agents on human fibrosarcoma cell lines. The capacity of ZOL and several antitumor agents to inhibit the growth of HT1080 cells was determined by employing the trypan blue dye exclusion method. Data from three independent experiments were collected, and Student's t-test was used to evaluate the efficacy of concurrent treatment with ZOL and other agents and to compare the effects of each anticancer agent alone. P-values of $<0.05$ were considered statistically significant and derived from two-sided statistical tests. $\mathrm{X}$-axis: a, control; b, $1.2 \mu \mathrm{M}$ of ZOL alone; $\mathrm{c}, 0.5 \mathrm{xIC} \mathrm{C}_{50}$ of antitumor drug alone; $\mathrm{d}$, combination of $\mathrm{b}$ with $\mathrm{c}$; $\mathrm{e}, 1.0 \mathrm{xIC} \mathrm{C}_{50}$ of antitumor drug; $\mathrm{f}$, combination of $\mathrm{b}$ with d. Y-axis is cell counts $\left(\times 10^{5}\right)$. (A) doxorubicin; (B) cisplatin; (C) etoposide; (D) 5-fluorouracil; (E) docetaxel; (F) paclitaxel; (G) gemcitabine; (H) methotrexate.

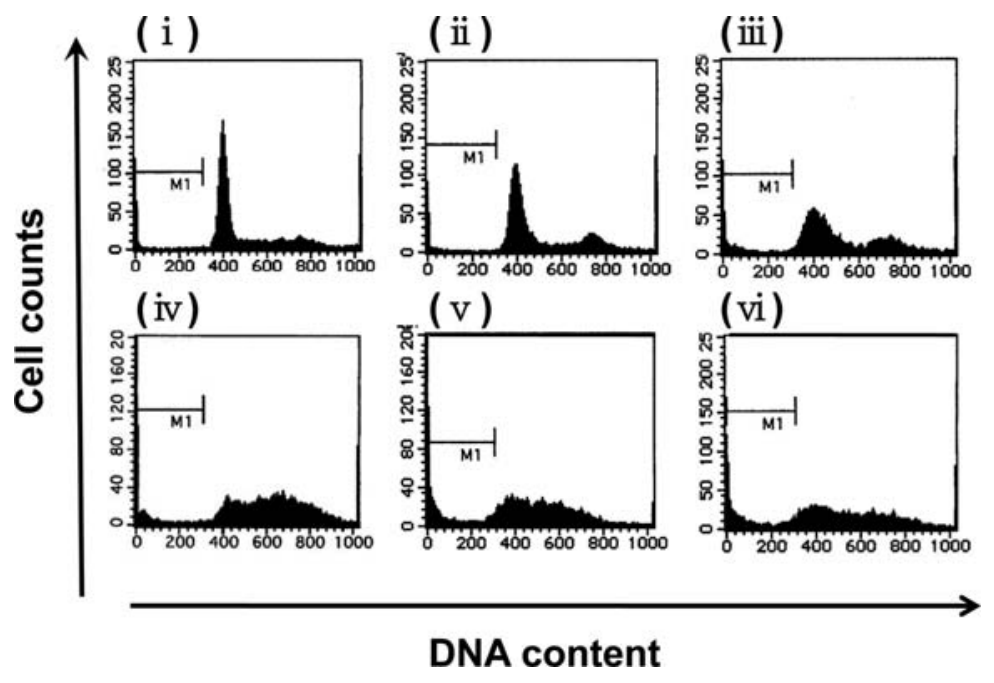

Figure 6. Cell cycle analysis of combined treatment of ZOL with etoposide. The effect of agents on the cell cycle was evaluated by flow cytometry of fibrosarcoma cells that had been exposed to different agent concentrations for $72 \mathrm{~h}$. $\mathrm{HT} 1080$ cells, untreated (i); $70 \mathrm{nM}$ (approximatelly equal to $0.5 \times \mathrm{IC}_{50}$ ) etoposide (ii); $140 \mathrm{nM}$ (approximatelly equal to $1.0 \mathrm{xIC}_{50}$ ) etoposide (iii); $1.2 \mu \mathrm{M} \mathrm{ZOL} \mathrm{(iv);} 1.2 \mu \mathrm{M}$ ZOL with $70 \mathrm{nM}$ etoposide (v); and $1.2 \mu \mathrm{M} \mathrm{ZOL}$ with $140 \mathrm{nM}$ etoposide (vi). Data on other antitumor agents alone, and the combination treatment of other antitumor agents with ZOL are not shown.

Table II. Sub-G1 (\%) in the cell cycle of HT1080 cells is shown.

\begin{tabular}{lrrrrrrrr}
\hline & A & B & \multicolumn{1}{c}{ C } & D & E & F & G & H \\
\hline 0.5 xIC $_{50}$ & 5.51 & 6.00 & 7.48 & 1.83 & 9.66 & 2.85 & 2.89 & 1.65 \\
ZOL1.2 $_{1.0 x+0.5 \text { IC }_{50}}$ & 29.23 & 14.99 & 32.15 & 11.4 & 43.98 & 11.43 & 12.34 & 4.84 \\
ZOL1 $1.2 \mu \mathrm{M}+1.0$ xIC $_{50}$ & 7.33 & 21.09 & 8.69 & 2.33 & 26.64 & 6.85 & 3.18 & 2.96 \\
\hline
\end{tabular}

HT1080 cells were treated with $0.5 \mathrm{xIC}_{50}$ and $1.0 \mathrm{xIC}_{50}$ of each agent, and $1.5 \mu \mathrm{M} \mathrm{ZOL}$ with $0.5 \mathrm{xIC}_{50}$ and $1.0 \mathrm{xIC}$ 50 of each agent. In both the treatment of $1.2 \mu \mathrm{M} \mathrm{ZOL}$ with $0.5 \mathrm{xIC}_{50}$ anticancer agent and $1.2 \mu \mathrm{M} \mathrm{ZOL}$ with $1.0 \mathrm{xIC}_{50}$ antitumor agent, the proportion of cells in the subG1 increased by $>20 \%$ by the combination of ZOL and doxorubicin, etoposide, and docetaxel. The data shown are representative of three independent experiments. A, doxorubicin; B, cisplatin; C, etoposide; D, 5-fluorouracil; E, docetaxel; F, paclitaxel; G, gemcitabine; H, methotrexate. 
sarcoma, and this is the first report. Nitrogen-containing bisphosphonates are known to block the mevalonate pathway by inhibiting the activation of small GTP-binding protein prenylation (11-13).

We have also shown that ZOL, one of the thirdgeneration bisphosphonates, blocked the prenylation of Rap1A proteins and induced cleaved caspase- 3 in a dose- and time-dependent manner in the fibrosarcoma cell line. Since the Ras/MAPK pathway is crucial for regulating intracellular signaling in the proliferation of tumor cells (34-36), blockage of the prenylation of small GTP-binding protein could result in blockage of the mevalonate pathway, which inhibits tumor growth. Recent studies have also shown that bisphosphonates can directly affect the proliferation and survival of a variety of tumor cells, including multiple myeloma, leukemia, prostate cancer, and osteosarcoma (4-7).

However, the precise mechanism is not yet sufficiently understood. In order to gain further insight into the mechanism of action, we have analyzed cell cycle changes using flow cytometry: ZOL facilitated apoptosis between the $\mathrm{S}$ phase and G2/M boundary. Furthermore, ZOL induced apoptotic bodies in fibrosarcoma cells when stained with DAPI. These results, cell cycle arrest and apoptosis induction, indicated that ZOL might cause DNA damage. However, as we have previously reported in osteosarcoma cells, it is difficult to clarify the mechanism only through alternation of the cell cycle.

The present study showed that the $\mathrm{IC}_{50}$ values of $\mathrm{ZOL}$ for fibrosarcoma cell lines ranged from 1 to $2 \mu \mathrm{M}$, although reports on leukemia, multiple myeloma, and osteosarcoma cells reported that the $\mathrm{IC}_{50}$ values of third-generation BPs ranged from 1 to $100 \mathrm{mM}$ (4-6). Following an infusion of the standard dose of zoledronic acid $(4 \mathrm{mg})$, peak plasma levels were only 1-2 $\mu \mathrm{M}$ (26). Therefore, considering the $\mathrm{IC}_{50}$, third-generation BPs could be very useful to treat patients with fibrosarcoma. However, ZOL is rapidly cleared from the circulation within $1-2 \mathrm{~h}$ (7). It is therefore likely that peripheral tumors are exposed to a low concentration of ZOL for only a few hours, and that the effects of ZOL alone might be insufficient in vivo.

Therefore, to increase the antitumor effects, we subsequently investigated the potential antitumor effects of ZOL combined the commonly used chemotherapeutic agents. ZOL augmented the cytotoxic effect and showed the synergistic induction of apoptosis in vitro when combined with paclitaxel, etoposide, cisplatin, and irrinotecan in lung cancer cells (20), with gemcitabine in colon cancer cells (21), with doxorubicin, paclitaxel, and tamoxifen in breast cancer cells $(25,28)$, with dexamethasone in myeloma cells $(39)$, and with paclitaxel, cisplatin, gemcitabine, and doxorubicin in murine osteosarcoma cells (24). In the present study, combined treatment of ZOL with paclitaxel, docetaxel, etoposide, cisplatin, gemcitabine, doxorubicin, or 5-fluorouracil showed a marked cytotoxic effect against human fibrosarcoma cells compared to the single use of these agents. Above all, the combined effect of etoposide, doxorubicin, and docetaxel tended to be marked regarding not only inhibition, but also the sub-G1 effect. These results suggest that combined treatment of $\mathrm{ZOL}$ with commonly used agents for soft tissue sarcoma also has the possibility of reducing the side effects of the antitumor agents. In the case of antitumor agents used for elderly patients, even if they are administered at a lower dose, equal effects may be expected when treated combined with ZOL.

There are some reports on the mechanism of the synergistic interaction between ZOL and chemotherapeutic agents. The synergisitic induction of apoptosis in breast cancer cells achieved by the combination of ZOL and paclitaxel or doxorubicin is sequence-dependent, with synergistic levels of apoptosis only being achieved when breast cancer cells are pre-treated with doxorubicin or paclitaxel followed by ZOL $(20,25,28,30)$. We showed that ZOL did not alter the cell cycle, but only increased the proportion of sub-G1 fibrosarcoma cells in the case of concurrent exposure. These results are thought to show that $\mathrm{ZOL}$ enhanced only the cytotoxic activity of anticancer agents, and did not influence the cell cycle. However, in human fibrosarcoma cells, like breast cancer cells, differences may be reflected in the antitumor effect based on the dosage method.

In contrast, ZOL combined with MTX administered to HT1080 cell lines showed antagonistic effects. This antagonistic effect of MTX was also seen in leukemic and murine osteosarcoma cells (40). It has been noted that one agent might reduce the cytotoxicity of the other agent by preventing cells from entering the specific phase in which they are most sensitive to the other agent. Although the reason for this antagonism has not been fully clarified, the simultaneous administration of ZOL with MTX might be counterproductive not only in the treatment of fibrosarcoma, but also in other cancers. Therefore, the clinical use of ZOL should be evaluated carefully to avoid adverse interactions.

When we consider that ZOL is rapidly cleared from the circulation, and even concurrent exposure exhibits a marked antitumor effect in vitro, sequential treatment involving the administration of other antitumor agents followed by ZOL might be clinically recommended, even though further studies on the dosage should be conducted.

These results suggest that $\mathrm{ZOL}$ could be beneficial in the treatment of fibrosarcoma patients. Furthermore, the combined administration of ZOL with other antitumor agents may be effective compared to the use of any of these agents or ZOL alone. Treatment using ZOL may improve the prognosis of patients with fibrosarcoma.

\section{Acknowlegements}

This work was supported by KAKENHI (Grant-in-Aid for Scientific Research C: 20591764 to H.M.).

\section{References}

1. Pritchard DJ, Sim FH, Ivins JC, Soule EH and Dahlin DC: Fibrosarcoma of bone and soft tissues of the trunk and extremities. Orthop Clin North Am 8: 869-881, 1977.

2. Pritchard DJ, Soule EH, Taylor WF and Ivins JC: Fibrosarcoma, a clinic-pathologic and statistical study of 199 tumors of the soft tissue of the extremities and trunk. Cancer 33: 888-897, 1974.

3. Scott SM, Reiman HM, Pritchard DJ and Ilstrup DM: Soft tissue fibrosarcoma. A clinicopathologic study of 132 cases. Cancer 64: 925-931, 1989.

4. Iguchi T, Miyakawa Y, Yamamoto K, Kizaki M and Ikeda Y: Nitrogen-containing bisphosphonates induce $S$-phase cell cycle arrest and apoptosis of myeloma cells by activating MAPK pathway and inhibiting mevalonate pathway. Cell Signal 15: 719-727, 2003. 
5. Nishida S, Fujii Y, Yoshioka S, Kikuichi S, Tsubaki M and Irimajiri K: A new bisphosphonate, YM529 induces apoptosis in HL60 cells by decreasing phosphorylation of single survival signal ERK. Life Sci 73: 2655-2664, 2003.

6. Kuroda J, Kimura S, Segawa H, et al: The third-generation bisphosphonate zolendronate synergistically augments the anti-PhC leukemia activity of imatinib mesylate. Blood 102: 2229-2235, 2003

7. Lee MV, Fong EM, Singer FR and Guenette RS: Bisphosphonate treatment inhibits the growth of prostate cancer cells. Cancer Res 61: 2602-2608, 2001.

8. Gouin F, Ory B, Redlini F and Heymann D: Zoledronic acid slows down rat primary chondrosarcoma development, recurrent tumor progression after intralesional curettage and increases overall survival. Int J Cancer 119: 980-984, 2006.

9. Kubo T, Shimosae S, Matsuo T, Tanaka K, Yasunaga Y, Sakai A and Ochi M: Inhibitory effects of a new bisphosphonate, minodronate, on proliferation and invasion of a variety of malignant bone tumor cells. J Orthop Res 24: 1138-1144, 2006.

10. Russel RG and Rogers MJ: Bisphosphonates: from the laboratory to the clinic and back again. Bone 25: 97-106, 1999

11. Bergstrom JD, Bostedor RG, Masarachia PJ, Reszka AA and Rodan G: Alendronate is a specific, nanomolar inhibitor of farnesyl diphosphate synthase. Arch Biochem Biophys 255: 491-494, 1999.

12. Van Beek E, Pieterman E, Cohen L, Lowwik C and Papapoulos S: Nitrogen-containing bishosphonates inhibit isopentenyl pyrophosphate isomerase/farnesyl pyrophosphate synthas activity with relative potencies corresponding to their antiresorptive potencies in vitro and in vivo. Biochem Biophys Res Commun 255: 235-242, 2001.

13. Dunford JE, Thompson K, Coxon FP, Luckman SP, Hahn FM, Poulter CD, Ebetino FH and Rogers MJ: Structure-activity relationships for inhibition of farnesyl diphosphate synthase in vitro and inhibition of bone resorption in vivo by nitrogencontaining bisphosphonates. J Pharmacol Exp Ther 296: 235-242, 2001

14. Benford HL, McGowan NW, Helfrich MH, Nuttall ME and Rogers MJ: Visualization of bisphosphonate-induced caspase-3 activity in apoptotic osteoclasts in vitro. Bone 28: 465-473, 2001.

15. Coxon FP, Helfrich MH, Van't Hof R, Sebti S, Ralston SH, Hamilton A and Rogers MJ: Protein geranylgeraylation is required for osteoclast formation, function, and survival: inhibition by bisphosphonates and GGTI-298. J Bone Miner Res 15: $1467-1476,2000$

16. Anderson KC, Kyle RA, Dalton WSm, Landowski T, Shain K, Jove R, Hazlehurst L and Berenson J: Multiple myeloma: new insights and therapeutic approaches. Hematology Am Soc Hematol Educ Program 1: 147-165, 2000.

17. Saad F, Gleason DM, Murray R, Tchekmedyian S, Venner P, Lacombe L, Chin JL, Vinholes JJ, Goas JA and Chen B; Zoledoronic acid Prostate Cancer Study Group: A randomized, placebo-controlled trial of zoledronic acid in patients with hormone-reflectory metastatic prostate carcinoma. J Natl Cancer Inst 94: 1458-1468, 2000.

18. Rosen LS, Gordon D, Tchekmedyian S, Yanagihara R, Hirsh V, Krzakowski M, Pawlicki M, de Souza P, Zheng M, Urbanowitz G, Reitsma D and Seaman JJ: Zoledronic acid versus placebo in the treatment of skeletal metastases in patients with lung cancer and other solid tumors: a phase III, double-blind, randomized trial, The Zoledronic acid Lung cancer and Other Solid Tumors Study Group. J Clin Oncol 21: 3150-3157, 2003.

19. Muraro M, Mereuta OM, Carraro F, Madon E and Faggioli F: Osteosarcoma cell line growth inhibition by zoledronate stimulated effector cells. Cell Immunol 249: 63-72, 2007

20. Boissier S, Magnetto S, Frappart L, Cusin B, Ebetino FH, Delmas PD and Clezardin P: Bisphosphonates inhibit prostate and breast carcinoma cell adhesion to unmineralized and mineralized bone extracellular matrices. Cancer Res 57: 3890-3894, 1997.

21. Boissier S, Ferreras M, Peyruchaud O, Magnetto S, Ebetino FH, Colombel M, Delmas PD, Delaisse JM and Clezardin P: Bisphosphonates inhibit breast and prostate carcinoma cell invasion, an early event in the formation of bone metastasis. Cancer Res 60: 2949-2954, 2000

22. Horie N, Murata H, Nishigaki Y, Matsui T, Segawa H, Nogawa M, Yuasa T, Kimura S, Maekawa T, Fushiki S and Kubo T: The third-generation bisphosphonates inhibit proliferation of murine osteosarcoma cells with induction of apoptosis. Cancer Lett 238: $111-118,2006$
23. Koto K, Horie N, Kimura S, Murata H, Sakabe T, Matsui T, Watanabe M, Adachi S, Maekawa T, Fushiki S and Kubo T: Clinically relevant dose of zoledronic acid inhibits spontaneous lung metastasis in a murine osteosarcoma model. Cancer Lett 274: 271-278, 2009.

24. Horie N, Murata H, Kimura S, Takeshita H, Sakabe T, Matsui T, Maekawa T, Kubo T and Fushiki S: Combined effects of a thirdgeneration bisphosphonate, zoledronic acid with other anti-cancer agents against murine osteosarcoma. Br J Cancer 96: 255-261, 2007.

25. Neville-Webbe HL, Evans CA, Coleman RE and Holen I: Mechanisms of the synergistic interaction between the bisphosphonate zoledoronic acid and the chemotherapy agent paclitaxel in breast cancer cells in vitro. Tumor Biol 27: 92-103, 2006.

26. Jagdev SP, Coleman RE, Shipman CM, Rostami-HA and Croucher PI: The bisphosphonate, zoledronic acid, induces apoptosis of breast cancer cells: evidence for synergy with paclitaxel. Br J Cancer 84: 1126-1134, 2001

27. Kubo T, Shimose S, Matsuo T, Sakai A and Ochi M: Efficacy of a nitrogen-containning bisphosphonate, minodronate, in conjunction with a p38 mitogen activated protein kinase inhibitor or doxorubicine against malignant tumor cells. Cancer Chemother Pharmcol 62: 111-116, 2008.

28. Ottewell PD, Mönkkönen H, Jones M, Lefley DV, Coleman RE and Holen I: Antitumor effects of doxorubicin followed by zoledronic acid in a mouse model of breast cancer. $J$ Natl Cancer Inst 100: 1167-1178, 2008.

29. Ottewel PD, Deux B, Mönkkönen H, Cross S, Coleman RE, Clezardin P and Holen I: Differential effect of doxorubicin and zoledoronic acid on intraosseus versus extraosseus breast tumor growth in vivo. Clin Cancer Res 14: 4658-4666, 2008.

30. Neville-Webbe HL, Rostami-Hodjegan A, Evans CA, Coleman RE and Hole I: Sequence- and schedule-dependent enhancement of zoledronic acid induced apoptosis by Doxorubicin in breast and prostate cancer cells. Int J Cancer 113: 364-371, 2005

31. Slovak ML, Ho JP, Bhardwaj G, Kurz EU, Deeley RG and Cole SP: Localization of a novel multidrug resistance-associated gene in the HT1080/DR4 and H69AR human tumor cell lines. Cancer Res 53: 3221-3225, 1993.

32. Slovak ML, Ho J P, Cole SPS, et al: The LRP gene encoding a major vault protein associated with drug resistance maps proximal to MRP on chromosome 16. Evidence that chromosome breakage plays a key role in MRP or LRP gene amplification. Cancer Res 55: 4214-4219, 1995.

33. Reszka AA, Halasy-Nagy J and Rodan GA: Nitrogenbisphosphonates block retinoblastoma phosphorylation and cell growth by inhibiting the cholesterol biosynthetic pathway in a keratinocyto model for esophageal irritation. Mol Pharmacol 59: 193-202, 2001

34. Turhan AG, Solary E, Vainchenker W and Dusanter-Fourt I: Molecular pathophysiology of chronic myelogeneous leukemia. Hematol Cell Ther 40: 217-221, 1998.

35. Neri A, Knowles DM, Greco A, McCormick F and DallaFavera R: Analysis of RAS oncogene mutations in human lymphoid malignancies. Proc Natl Acad Sci USA 85: 92689272, 1998.

36. Katz ME and McCormick F: Signal transduction from multiple Ras effectors. Curr Opin Genet Dev 7: 75-79,1997.

37. Matsumoto S, Kimura S, Segawa H, et al: Efficacy of the third-generation bisphosphonate, zoledronic acid alone and combined with anti-cancer agents against small cell lung cancer cell lines. Lung Cancer 47: 31-39, 2005.

38. Trojan J, Kim SZ, Engels K, Kriener S, Mitrou PS and Chow KU: In vitro chemosensitivity to gemcitabine, oxaliplatin and zoledronic acid predicts treatment response in metastatic gastric cancer. Anticancer Drugs 16: 87-91, 2005.

39. Tassone P, Forciniti S, Galea E, Savino R, Turco MC, Iacopino P, Tagliaferri P, Morrone G, Ciliberto G and Venuta S: Growth inhibition and synergistic induction of apoptosis by zoledronic acidedronate and dexamethasone in human myeloma cell lines. Leukemia 14: 841-844, 2000.

40. Kimura S, Kuroda J, Segawa H, Sato K, Nogawa M, Yuasa T, Ottmann OG and Maekawa T: Antiproliferative efficacy of the third-generation bisphosphonate, zoledronic acid, combined with other anticancer drugs in leukemic cell lines. Int J Hematol 79: 37-43, 2004. 